Research Article

\title{
Prevalence and Intensity of Gastrointestinal Parasites in Donkeys in Selected Abattoirs in Kenya
}

\author{
Nancy Mulwa $\mathbb{D}^{1},{ }^{1}$ Samuel Githigia, ${ }^{1}$ Davis Karanja, ${ }^{1}$ Cecilia Mbae $\mathbb{D}^{2},{ }^{2}$ Eberhard Zeyhle, ${ }^{3}$ \\ Erastus Mulinge, ${ }^{2}$ Japhet Magambo, ${ }^{3}$ and Kennedy Ogolla $\mathbb{D}^{1}$ \\ ${ }^{1}$ Department of Veterinary Pathology, Microbiology and Parasitology, University of Nairobi, P.O. Box 29053-00625, \\ Nairobi, Kenya \\ ${ }^{2}$ Kenya Medical Research Institute, P.O. Box 19464-00202, Nairobi, Kenya \\ ${ }^{3}$ Meru University of Science and Technology, P.O. Box 972-60200, Meru, Kenya \\ Correspondence should be addressed to Nancy Mulwa; nancyndinda4@gmail.com
}

Received 30 September 2019; Revised 2 December 2019; Accepted 23 January 2020; Published 9 March 2020

Academic Editor: Michael Ivan Lindinger

Copyright (C) 2020 Nancy Mulwa et al. This is an open access article distributed under the Creative Commons Attribution License, which permits unrestricted use, distribution, and reproduction in any medium, provided the original work is properly cited.

\begin{abstract}
The aim of this study was to determine the prevalence and intensity of gastrointestinal parasites in donkeys slaughtered in Kinamba, Mogotio, and Lodwar slaughterhouses and their association with several host factors. A survey was done between July and September 2017 in three slaughterhouses. Faecal samples were collected per rectum from all the study donkeys for faecal egg counts (EPG) and morphological identification of the eggs. At slaughter, the gastrointestinal tracts were opened and examined visually, and all helminth parasites collected were subjected to morphological identification. Prevalence and intensity were calculated based on the helminth identified and EPG. A total of 282 donkeys were sampled. A majority of the donkeys ( $89 \%)$ were in poor body condition. Ten helminth parasite species were identified in $85.5 \%$ donkeys. They were Strongylus vulgaris (52.8\%), Parascaris equorum (20.2\%), Strongylus edentatus (12.1\%), Anaplocephala perfoliata (10.3\%), Setaria equina (3.5\%) Anaplocephala magna (2.5\%), Cylicocyclus auriculatus (2.1\%), Cyathostomum species (1.8\%), Strongylus equinus (0.4\%), and Triodontophorus serratus (0.4\%). A significant percentage (55.3\%) had no eggs in their feces, $39 \%$ had low infection, $5 \%$ had medium, and only $0.7 \%$ were heavily infected. Prevalence rates via use of the EPG showed Strongyles (44.7\%), Parascaris equorum (5.3\%), Oxyuris equi (11\%), Triodontophorus tenuicolis $(0.7 \%)$, Habronema species $(0.7 \%)$, and cestodes eggs $(0.4 \%)$. No significant differences were observed between fecal Strongylus egg count and age, sex, and pregnancy status. However, donkeys with poor body condition shed more Strongylus eggs in feces. Helminth infections are prevalent in donkeys in Kenya; however, this is not reflected in coprological analyses. These helminth parasites may contribute to poor body condition, ill health, and poor productivity of donkeys.
\end{abstract}

\section{Introduction}

Kenya has approximately 1,832,519 donkeys [1]. More than half of this population is being used for working in transport and tillage operations [1]. Donkeys are frequently involved in work for lengthy periods, and when released, they are left to browse and feed on less nutritive garbage. This has been associated with prospective negative effects in particular on their welfare and health status [2]. Gastrointestinal parasites are causes of the most prominent diseases in the donkey compared with other diseases [3]. Although donkeys appear resistant to many diseases, helminth infections are the most common cause of death besides retarding growth or decreasing work output [4]. In addition, parasites lead to distress and pain. Such infections exhibit a direct outcome on health and productivity [5]. This may lead to early demise or reduction in work output of affected donkeys and eventually reduction in income of the owner and community [5]. In a research carried out by Ahmed et al. [6] in Egypt, $98.45 \%$ of the donkeys sampled were infected by helminths and 22 species were identified. This is also similar to the study by Ismail et al. [7] who found an almost similar overall prevalence. Matthee et al. [8] identified 15 genera and 29 species of helminths in seven donkeys necropsied in South 
Africa, with Strongylus vulgaris being the most abundant and prevalent strongyle species. In Nigeria, strongyles were also identified as the most dominant species with $92 \%$ of the donkeys positive for the various gastrointestinal parasites. In India, on the contrary, Shrikhande et al. [9] established 82.9\% incidence with Strongylus species as the most common helminth infesting donkeys followed by Parascaris equorum. In Turkey, Uslu and Guclu [10] found out that the coprological prevalence of parasitic infections in donkeys was $100 \%$, whereas Muhammad et al. [11] in Pakistan established a lower prevalence for strongylosis. Eighty percent prevalence for strongyle egg infection was seen in donkeys in Mexico [12]. Ahmed et al. [6] found that more than $55 \%$ of donkeys also had high intensity (EPG greater than 1000). In Kenya, Karanja et al. [13] reported a low-tomoderate strongyle infection on fecal egg counts of the eight donkeys examined.

A study done in Nigeria established that age, sex, and season were not statistically associated with the risk of helminth infection; however, body condition score, settlement, anthelmintic medication history, and management practices were significantly associated with the risk of gastrointestinal helminthosis [14]. No significant differences were noted in terms of age and sex for infected donkeys in Ethiopia [15].

Similar studies in Kenya done by Karanja et al. and Lewa et al. $[13,16]$ showed that gastrointestinal parasites were prevalent in donkeys. These previous studies in Kenya involved few donkeys from Kiambu County. More recent studies involving a larger number of donkeys are lacking in Kenya. Additionally, host factors and intensity have not been studied. This study therefore aimed at quantifying and qualifying the gastrointestinal parasites in donkeys, their associations with donkey welfare, as well as the public health as some of parasites harbored by donkeys are of zoonotic potential. The results will help in planning and implementation of control measures for the improvement of donkey health and productivity in Kenya.

\section{Materials and Methods}

2.1. Study Design and Sampling. A cross-sectional study was undertaken in three donkey slaughterhouses between July and September, 2017. Faecal samples were collected from the rectum of individual donkeys, and upon slaughter, the gastrointestinal tract was opened and whole helminths collected for laboratory analyses in the Department of Veterinary Pathology, Microbiology, and Parasitology at the University of Nairobi. Data on age, sex, body condition score, origin of the donkey, and pregnancy status were observed and recorded in the data capture sheet.

2.2. Study Sites. The following three donkey export slaughterhouses were purposively selected: Goldox Limited, Mogotio, Baringo County; Star Brilliant Export Slaughterhouse, Naivasha, Nakuru County; and Silzha Limited, Lodwar, Turkana County (Figure 1). Lodwar is the largest town in northwestern Kenya, located west of Lake Turkana.
It has a hot desert climate with little rainfall and high temperature throughout the year. It lies between longitudes $34^{\circ} 30^{\prime}$ and $36^{\circ} 40^{\prime}$ east and between latitudes $1^{\circ} 30^{\prime}$ and $5^{\circ} 30^{\prime}$ north. The key economic activity is pastoralism as depicted by livestock rearing. The major livestock reared include cattle, donkeys, camels, and goats [17]. Mogotio is a town in Baringo County. The economy of Baringo County is based on agricultural activities with hides and skin as one of the main livestock products. It is located between longitudes $35^{\circ} 30^{\prime}$ and $36^{\circ} 30^{\prime}$ east and between latitudes $0^{\circ} 10^{\prime}$ south and $1^{\circ} 40^{\prime}$ north [17]. Naivasha town is a major significant urban center in Nakuru County. Nakuru County lies between longitudes $35^{\circ} 28^{\prime} \mathrm{W}$ and between latitudes $0^{\circ} 13^{\prime} \mathrm{N}$ and $1^{\circ} 10^{\prime} \mathrm{S}$. Agriculture is the pillar of this county's economy [17].

2.3. Sample Size Determination. The sample size was determined according to the number of animals presented for slaughter during the study period. In Lodwar and Baringo County, every fourth and tenth donkey presented for slaughter was examined, respectively. In Naivasha County, where logistical operations of the slaughterhouse were friendly, all donkeys presented for slaughter during the study period were examined.

2.4. Host Factor Determination. The age and sex were estimated based on the size of the donkey and observation of the external genitalia during general examination. The pregnant females were identified by the observation of a fetus in utero during evisceration. The body condition of donkeys was obtained by visual appraisal and scored on a scale of 1 to 5 (1-poor, 2-moderate, 3-ideal, 4-fat, and 5obese) according to [18].

2.5. Sample Collection and Processing. The entire gastrointestinal system and the liver were visually examined and helminths collected. They were rinsed gently in water and preserved in $70 \%$ ethanol for further analysis. The parasites were then identified based on their gross and/or microscopic morphological features as described by Soulsby [19]. Cestodes recovered were processed according to a technique described by the International Institute of Parasitology [20] and identified morphologically according to [19].

Faecal samples (5-10 grams) were collected directly from the rectum of each animal. The sample was labeled, preserved in $70 \%$ ethanol, and analyzed using the standard McMaster egg count technique according to [21]. Helminth eggs and protozoal cysts encountered were identified morphologically [19]. The intensity of infection for the eggs was determined by counting the number of eggs per gram of feces (EPG) and classified as none (0), low (1-500), medium (501-1000), or high (>1000) [19].

2.6. Data Analysis. The data were entered into the Microsoft Office Excel data sheet (2007) and coded. Thereafter, proportions were calculated for the various helminth infections. It was later transferred into statistical software Statistical Package for Social Science (SPSS), version 22, for descriptive 


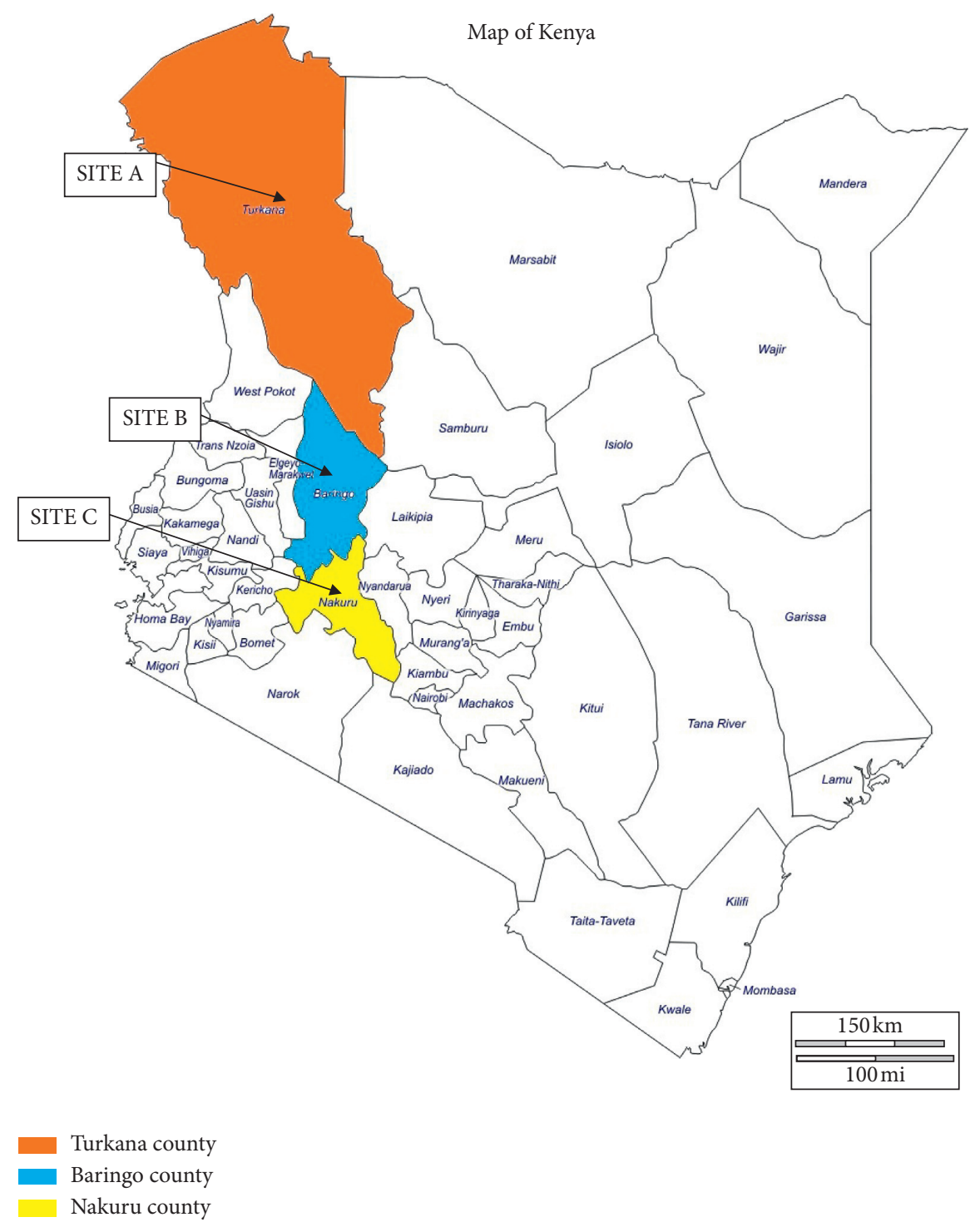

Figure 1: Map of Kenya showing the three counties where donkey abattoirs are located: Turkana (a), Baringo (b), and Nakuru (c) counties.

statistics, calculations of frequencies, and chi-square tests. Fisher's exact test was used to determine the strength of association between the different variables. The level of statistical significance was set at $p<0.05$. The prevalence of helminth infection was determined as follows:

$$
\text { prevalence }=\frac{(\text { number positive })}{(\text { number examined })} \times 100 \text {. }
$$

Four intensity classes for strongyle egg counts were categorized, and percentages were obtained for each class using the Microsoft Excel data sheet.

\section{Results}

3.1. Characteristics of Donkeys Sampled. A total of 282 donkeys were examined. Of these, $40 \%(114 / 282)$ were females, while $60 \%(168 / 282)$ were males. Ninety-four percent were adults, whereas $6 \%$ were juveniles. A high proportion of the animals had poor body condition (89\%) with only $11 \%$ having moderate body condition. Nineteen of the sampled female donkeys (114) were pregnant.

3.2. Prevalence of Helminth/Protozoal Infection. Fifty-six percent $(157 / 282)$ of the fecal samples analyzed were positive for the various helminth eggs. The prevalence of the various helminth eggs was strongyle eggs (44.7\%; 126/282), Parascaris equorum (5.3\%; 15/282), Oxyuris equi $(1.1 \% ; 3 / 282)$, Triodontophorus tenuicolis $(0.7 \% ; 2 / 282)$ and Habronema spp. $(0.7 \% ; 2 / 282)$, and cestodes eggs $(0.4 \% ; 1 / 282)$. Less than $1 \%(2 / 282)$ of the donkeys were identified positive for Giardia cysts, while $2.1 \%$ (6/282) were positive for coccidian oocysts. The strongyle egg counts ranged from 0 to 1900 with an average of 136.52 eggs per gram (EPG) followed by Parascaris equorum with a mean of 13.12 EPG. The least was the cestode egg with a mean of 0.35 EPG. Coccidian oocysts and Giardia cysts had an average of 3.90 and 2.13 oocysts cyst per gram of feces, respectively. The means and ranges of the various eggs and cysts were also demonstrated (Table 1). The 
TABLE 1: Infection intensity ranges and means \pm standard error of the mean of helminth eggs, cysts, and oocysts recovered from the fecal samples of donkeys $(n=282)$.

\begin{tabular}{lccc}
\hline Identity of the eggs/cysts & Intensity ranges & Mean \pm standard error of the mean & Prevalence $(\%)$ \\
\hline Cestode spp. & $0-100$ & $0.35 \pm .355$ & 0.4 \\
Coccidia spp. & $0-500$ & $3.90 \pm 2.027$ & 2.1 \\
Giardia spp. & $0-400$ & $2.13 \pm 1.584$ & 0.4 \\
Habronema spp. & $0-100$ & $0.71 \pm .501$ & 0.7 \\
Oxyuris equi & $0-300$ & $2.13 \pm 1.323$ & 1.1 \\
Parascaris equorum & $0-500$ & $13.12 \pm 3.660$ & 5.3 \\
Strongyle eggs & $0-1900$ & $136.52 \pm 14.153$ & 44.7 \\
Triondontophorus tenuicolis & $0-100$ & $0.71 \pm .501$ & 0.7 \\
\hline
\end{tabular}

typical strongyle egg and Parascaris equorum egg have been illustrated in Figure 2.

Mixed infections were detected in $29.4 \%$ (83/282) of the animals, whereas $42.9 \%(119 / 282)$ animals had a single helminth infection. From the helminth identification done in the parasitology laboratory, the animals with one, two, and three types of helminths were $58.9 \%$ (119/202), 32.7\%\% (66/202), and 8.4\%\% (17/202), respectively. Prevalence of helminths was slightly higher in females $75.4 \%$ than males $69 \%(p=0.282)$.

3.3. Intensity of Helminth Infection according to Fecal Egg Count. Fifty-five percent (156/282) of the donkeys had no egg present, $39 \%(110 / 282)$ had a low infection rate (up to $500 \mathrm{EPG}), 5 \%(14 / 282)$ had a medium infection rate (501-1000 EPG), and 0.7\% (2/282) having a high infection rate ( $>1000$ EPG) as shown in Table 2. Coprological analysis showed low Parascaris equorum infection (Table 3 ).

3.4. Prevalence of Various Helminth Species. The overall prevalence for the various helminths was $71.6 \%(202 / 282)$. The parasites identified at postmortem included Anaplocephala magna 2.5\% (7/282), Anaplocephala perfoliata 10.3\% (29/282), Cylicocyclus auriculatus $2.1 \%$ (6/282), cyathostome species 1.8\% (5/282), Parascaris equorum 20.2\% (57/282), Strongylus edentatus 12.1\% (34/282), Strongylus equinus $0.4 \%$ (1/282), Strongylus vulgaris 52.8\% (149/282), Setaria equina $3.5 \%$ (10/282), and Triodontophorus serratus $0.4 \%$ (1/ 282) as shown in Figure 3.

3.5. Donkey Risk Factors. The strongyle fecal egg counts did not significantly differ between the age groups $(p>0.05)$ and sex $(p>0.05)$. However, the strongyle egg counts recorded in donkeys with poor body condition were significantly different $(p=0.001)$ from those recorded in those with moderate body condition. Pregnant females had no statistically significant fecal egg count $(178 \pm 265.8$ EPG $)$ as compared with the nonpregnant females $(141.1 \pm 228.5 \mathrm{EPG})$ $(p=0.522)$. There was no association between age and sex of a donkey and the prevalence of the various helminth species identified at postmortem $(p=0.739 ; p=0.624)$. Additionally, no significant difference between the prevalence of the various helminth species identified at postmortem and sex of the animal was seen (see Table 4). A higher prevalence was noted in donkeys with a poor body condition score in exception of Cylicocyclus auriculatus and Anaplocephala magna. A significant difference was noted in the prevalence of Strongylus vulgaris (Table 4).

\section{Discussion}

Our studies confirm the studies done by Karanja et al. and Lewa et al. [13, 16] that gastrointestinal parasites are prevalent in donkeys in Kenya. The overall prevalence of the various helminths in our study was $71.6 \%$. This differs from a study done in Ethiopia where the prevalence was established at $96.9 \%$ for helminth species [22]. In Nigeria, Jajere et al. [14] established an overall prevalence of $98.3 \%$ after fecal analysis, whereas in our study, the overall prevalence of the helminth eggs was $56 \%$. This difference in the prevalence of fecal egg count could be attributed to differences in geographical zones. The majority of the donkeys in our study (89\%) had a poor body condition score. This could be due to helminthosis in conjunction with a low plane of nutrition as a majority of the donkeys with poor body condition were highly infected. This is in agreement with the findings of Saul et al. [4] who reported helminth infections as the most common cause of death besides retarding growth or decreasing work output, in addition to distress and pain. Ten helminth species identified in our study included Anaplocephala magna, Anaplocephala perfoliata, Cylicocyclus auriculatus, cyathostome species, Parascaris equorum, Strongylus edentatus, Strongylus equinus, Strongylus vulgaris, Setaria equina, and Triodontophorus serratus. These findings differ from those of Ahmed et al. [6] from Egypt, who found the overall prevalence to be $98.5 \%$ with 22 adult helminth species. Ahmed et al. [3] from Nigeria reported 92\% prevalence on the various gastrointestinal parasites. Our findings differ, and this could be attributed to the different geographical regions and management systems. The most common helminth species in our study was Strongylus vulgaris $(52.8 \%)$; this is similar to other studies done $[8,9,22]$. In Kenya, Lewa et al. [23] found 14 species of helminths in the six donkeys examined at necropsy, whereas seven species of helminths were found by Karanja et al. [13]. Our study has identified additional species which include Triodontophorus serratus, Cylicocyclus auriculatus, and Anaplocephala magna. Habronema species eggs were however identified in the faecal samples of two donkeys in our study. The differences in species identified in our study could be due to the larger sample size and also due to the origin of the slaughtered donkeys as the majority of the 


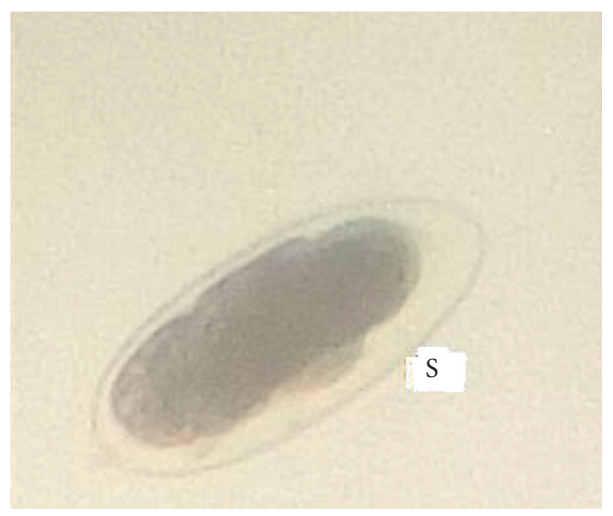

(a)

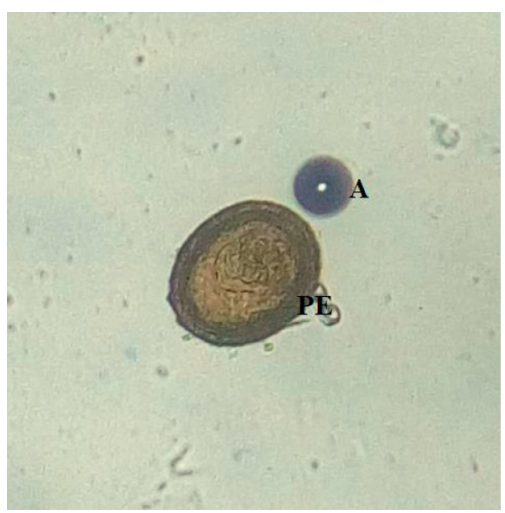

(b)

Figure 2: Photomicrograph showing (a) a typical strongyle-type egg (S), thin shelled and ovoid in shape on the left side, and (b) a spherical brownish egg of Parascaris equorum (PE) and an artifact; air bubble (A) from two different donkeys.

TABle 2: Proportion of the Strongylus egg infection rates for slaughtered donkeys.

\begin{tabular}{lcc}
\hline Level of infection & No. of donkeys & Proportion (\%) \\
\hline High & $2 / 126$ & 1.6 \\
Medium & $14 / 126$ & 11.1 \\
Low & $110 / 126$ & 87.3 \\
None & $156 / 282$ & 55.3 \\
\hline
\end{tabular}

TABle 3: Proportion of the Parascaris equorum egg infection rates for slaughtered donkeys.

\begin{tabular}{lcc}
\hline Level of infection & No. of donkeys & Proportion (\%) \\
\hline High & 0 & 0 \\
Medium & 0 & 0 \\
Low & 15 & 5.3 \\
None & 267 & 94 \\
Total & 282 & 100 \\
\hline
\end{tabular}

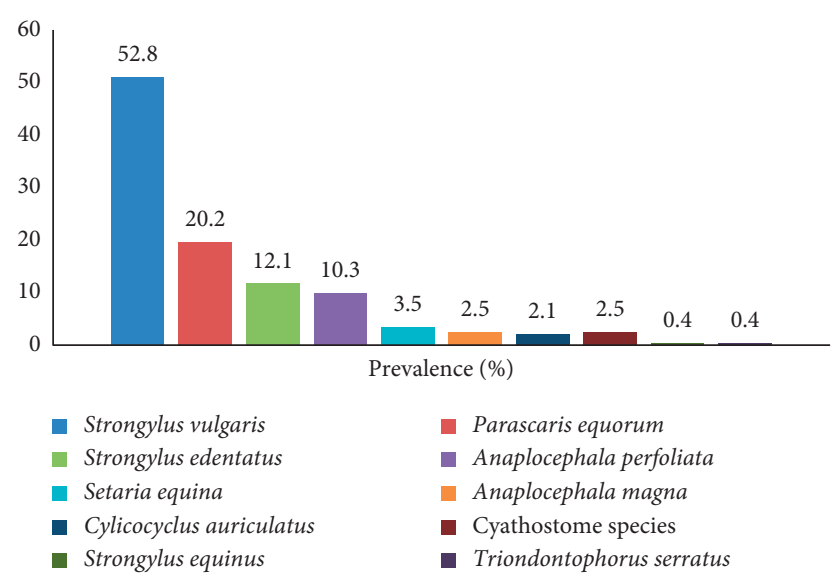

Figure 3: Prevalence of the various helminth parasites in the slaughtered donkeys.

donkeys originated from the arid and semiarid areas of Kenya. In the previous studies, the donkeys were from Kiambu County of Kenya, which experiences cool and wet climate. Getachew et al. [24] observed $8 \%$ prevalence of
Anaplocephala perfoliata in working donkeys in Ethiopia, and this is almost similar to the prevalence found in our study (10\%).

Fecal egg examination in our study revealed; $44.7 \%$ strongyle eggs, 5.3\% Parascaris equorum, 1.1\% Oxyuris equi, 0.7\% Triondontophorus tenuicolis and 0.7\% Habronema species, and $0.4 \%$ cestode eggs. According to a report by Ahmed et al. [6], from Egypt, the fecal egg examination showed 99\% strongyle, 80\% Fasciola, 51\% Parascaris, 30\% Gastrodiscus, 11\% Strongyloides westeri, 8\% Anaplocephala perfoliata cestodes, and 2\% Oxyuris equi infection prevalence. The infection level in our study was lower, and this could be attributed to the seasons in Kenya as the animals were sampled during the dry season. Dry conditions are linked to a lower prevalence and intensity of helminth infection [25], meaning the values could probably be high during the rainy seasons. The egg count for the strongyle eggs in our study ranged from 0 to $1900 \mathrm{EPG}$, which is low as compared with that in the study by Vercruysse et al. [26] from Burkina Faso who established an egg count range of 100-9,200 EPG for strongyle eggs. Karanja et al. [13], in Kenya, found the infection to be low to moderate for strongyle infection; this is in agreement with the results of this study as most donkeys had an egg count of 0-499 EPG. The number of adult helminths observed was however high, and this shows that it does not relate to the fecal egg count. As observed in this study, a fecal egg count of zero did not mean the donkey was helminth-free. The donkey could be harboring a majority of the immature stages of the helminths in high numbers, and hence, the resultant was low/no egg count. This is in agreement with an observation made by Matthews and Burden [27] who stated that donkeys can harbor substantial levels of helminths, but the parasites are not detectable via routine fecal egg count (FEC) analysis. The prevalence of Giardia cysts in our study was $0.7 \%$, which is similar to that in the study by De Souza et al. [28] from Brazil whose prevalence was $0.5 \%$. A recent study in China by Zhang et al. [29] reported a prevalence of $15.47 \%$ for Giardia intestinalis in donkeys. The high prevalence is due to the sensitive technique of diagnosis used, which is polymerase chain reaction. Our study is the first to establish and 
TABLE 4: Relative prevalence of the various helminth species according to sex and body condition scores (BCS) and their respective $p$ values.

\begin{tabular}{|c|c|c|c|c|c|c|}
\hline Helminth species & $\begin{array}{c}\text { Males }(n=168) \text {, } \\
\%\end{array}$ & $\begin{array}{c}\text { Females }(n=114) \\
\%\end{array}$ & $\begin{array}{l}p \text { value- } \\
\text { sex }\end{array}$ & $\begin{array}{c}\text { Moderate BCS }(n=32) \text {, } \\
\%\end{array}$ & $\begin{array}{c}\text { Poor BCS }(n=250) \text {, } \\
\%\end{array}$ & $\begin{array}{l}p \text { value- } \\
\text { BCS }\end{array}$ \\
\hline Parascaris equorum & 19.6 & 21.1 & 0.765 & 15.6 & 20.8 & 0.642 \\
\hline Setaria equina & 2.4 & 5.3 & 0.21 & 3.1 & 3.6 & 1.000 \\
\hline Strongylus edentatus & 9.5 & 15.8 & 0.136 & 12.5 & 12 & 1.000 \\
\hline Strongylus vulgaris & 48.2 & 59.6 & 0.069 & 34.4 & 55.2 & $0.037^{*}$ \\
\hline Strongylus equinus & 0.6 & 0.0 & 1.000 & 0 & 0.4 & 1.000 \\
\hline Cylicocyclus auriculatus & 3.0 & 0.9 & 0.407 & 3.1 & 2 & 0.518 \\
\hline Cyathostomum spp. & 3.0 & 0.0 & 0.073 & 0 & 2 & 1.000 \\
\hline Anaplocephala magna & 3.6 & 0.9 & 0.248 & 3.1 & 2.4 & 0.574 \\
\hline $\begin{array}{l}\text { Anaplocephala } \\
\text { perfoliata }\end{array}$ & 8.9 & 12.3 & 0.426 & 6.2 & 10.8 & 0.551 \\
\hline $\begin{array}{l}\text { Triodontophorus } \\
\text { serratus }\end{array}$ & 0.6 & 0.0 & 1.000 & 0 & 0.4 & 1.000 \\
\hline
\end{tabular}

* Statistically significant.

document the prevalence of Giardia in donkeys in Kenya. Coccidian oocysts on the other hand occurred at $2.1 \%$, and this differs from the findings of De Souza et al. [28] who found a prevalence of $0.5 \%$. A recent study by Nakayima et al. [30] has shown a prevalence of $3.85 \%$ for Eimeria species, which is closer to the findings in our study.

There were no significant differences in the strongyle egg count between the adults and the juveniles. This agrees with the findings of Jajere et al. [14] who reported that age and sex were not statistically associated with the risk of helminth infection. This is in contrary to the study in Lesotho which indicated an inverse association between age and intensity of strongyle infection [25, 31]. Additionally, no significant differences were observed in strongyle eggs shed between the males and the females. This could suggest that the management of the animals at the farm level is the same. This is in contrary to the study [31] in Lesotho where a significantly higher strongyle infection was observed in female horses, and the difference could be because their study was done on working horses. A significant difference was seen between the strongyle eggs shed and body condition scores in our study, and this is in agreement with the previous study [25] that reported animals with poor body condition had a high fecal egg count. Ibrahim et al. [22] also found out that donkeys with a poor body condition score had a high prevalence of helminth parasites as compared with donkeys with a good body condition score. Mohammed Jajere et al. [14] also showed that the body condition score was associated with the risk of gastrointestinal helminthosis. This is in agreement with our study that showed a high prevalence of strongyle egg counts in donkeys with a poor body condition score. A study carried out in Morocco by Crane et al. [32] showed considerable increase in the body condition score in the equids that received anthelmintic treatment contrary to those in which a placebo was administered. With regard to the prevalence of the helminths, there was no association found between the body condition score and the prevalence of the helminths. This is in agreement with a study done by Tesfu et al. [33] who reported no association of nematode infection with regard to the body condition score of the donkeys. In our study, both moderate and poor body condition score groups were equally infected by helminths and could suggest that a body condition score of 2 or less could indicate a need for therapeutic intervention with antihelminthic drugs. Our study also revealed that there was no association between age and sex and helminth infection. This is in agreement with the findings of Ibrahim et al. [22] who found that all age groups were equally affected. For sex, however, Attia et al. [34] found that females were majorly affected compared with males. This differs from the findings of our study, and this could be because both male and female donkeys are raised in the same environmental condition, which in Kenya is mostly free range. Additionally, in our study, a high number of animals presented for slaughter were adults.

\section{Conclusion}

Helminth infection is prevalent in donkeys in Kenya. The strongyles are the most dominant compared with other helminths. These diverse internal parasites affect health and production of donkeys. A majority of the donkeys had a poor body condition score, and this has shown an association with helminth infection. Some of the parasites reported herein may be zoonotic; therefore, further studies are needed to prove this assumption in addition to hematological studies to establish the full range of parasitic infections in donkeys.

\section{Data Availability}

Any additional data is available upon request via the corresponding author Dr. Nancy Mulwa through nancyndinda4@gmail.com.

\section{Conflicts of Interest}

The authors declare that they have no conflicts of interest.

\section{Acknowledgments}

The authors wish to acknowledge the slaughterhouse management of various facilities for allowing them to sample the donkeys. The authors also thank the laboratory personnel of the University of Nairobi at the Department of Veterinary Pathology Microbiology and Parasitology for their professional contribution during sample processing. The survey in the field was financially assisted through 
CESSARI Project (Cystic Echinococcosis in sub-Saharan Africa Research Initiative).

\section{References}

[1] Government of Kenya, Kenya Population and Housing Census Results: Ministry of State for Planning, National Development and Vision 2030, Government of Kenya, Nairobi, Kenya, 2009.

[2] S. Mekuria and R. Abebe, "Observation on major welfare problems of equine in Meskan district, Southern Ethiopia," Livestock Research for Rural Development, vol. 22, no. 3, 2010.

[3] M. I. Ahmed, A. N. Tijjani, and A. R. Mustapha, "Survey for common diseases and management practices of donkeys (Equus asinus) in Borno state Nigeria," Nigerian Veterinary Journal, vol. 29, no. 3, pp. 1-5, 2008.

[4] C. Saul, L. Siefert, and J. Opuda-Asibo, "Disease and health problems of donkeys: a case study from Eastern Uganda," in Proceedings of the International Animal Traction Network for Eastern and Southern Africa (ATNESA'97), Debre Zeit, Ethiopia, February 1997.

[5] A. Mohamee, K. Hailemariam, and M. Yimer, "Major gastrointestinal parasites of donkey in and around Jigjiga, Somali region, Ethiopia," Advances in Biological Research, vol. 11, no. 3, pp. 144-149, 2017.

[6] N. E. Ahmed, L. M. El-Akabawy, M. Y. Ramadan, and A. M. M. Radwan, "Studies on helminth parasites in necropsied donkeys in Egypt," Benha Veterinary Medical Journal, vol. 1, pp. 153-162, 2011.

[7] A. A. Ismail, N. K. Ahmed, A. E. Bashar, H. I. Seri, E. TiganiAsil, and A. D. Abakar, "A survey of seasonal gastrointestinal parasitic infections in donkeys from a Semiarid sub-Saharan region, Sudan," Journal of Pathogens, vol. 2016, Article ID 4602751, 8 pages, 2016.

[8] S. Matthee, R. C. Krecek, and S. A. Milne, "Prevalence and biodiversity of helminth parasites in donkeys from South Africa," Journal of Parasitology, vol. 86, no. 4, pp. 756-763, 2000.

[9] G. B. Shrikhande, S. G. Rewatkar, S. S. Deshmukh, D. K. Maske, and Y. M. Raghorte, "The incidence of helminth parasites in donkeys," Veterinary World, vol. 2, no. 6, p. 224, 2009.

[10] U. Ğ. U. R. Uslu and F. Guclu, "Prevalence of endoparasites in horses and donkeys in Turkey," Bulletin-Veterinary Institute in Pulawy, vol. 51, no. 2, p. 237, 2007.

[11] W. Muhammad, M. S. Khan, A. Z. Durrani et al., "Prevalence of gastrointestinal parasites, chemotherapy and haematology of strongylosis in donkeys of district Lahore, Pakistan," International Journal of Current Microbiology and Applied Sciences, vol. 3, no. 7, pp. 198-207, 2014.

[12] F. A. Burden, N. Du Toit, M. Hernandez-Gil, O. Prado-Ortiz, and A. F. Trawford, "Selected health and management issues facing working donkeys presented for veterinary treatment in rural Mexico: some possible risk factors and potential intervention strategies," Tropical Animal Health and Production, vol. 42, no. 4, pp. 597-605, 2010.

[13] D. N. Karanja, T. A. Ngatia, and J. G. Wandera, "Some common gastrointestinal parasites observed in Kenyan donkeys," Bulletin of Animal Health and Production in Africa, vol. 42, pp. 75-76, 1994.

[14] S. Mohammed Jajere, J. Rabana Lawal, A. Mohammed Bello, Y. Wakil, U. Aliyu Turaki, and I. Waziri, "Risk factors associated with the occurrence of gastrointestinal helminths among indigenous donkeys (Equus asinus) in Northeastern
Nigeria," Scientifica, vol. 2016, Article ID 3735210, 7 pages, 2016.

[15] B. Bogale, Z. Sisay, and M. Chanie, "Strongyle nematode infections of donkeys and mules in and around Bahirdar, Northwest Ethiopia," Global Veterinaria, vol. 9, no. 4, pp. 497-501, 2012.

[16] A. K. Lewa, T. A. Ngatia, W. K. Munyua, and N. E. Maingi, "Pathological lesions associated with internal parasitosis in donkeys in Kiambu district in Kenya," in Proceedings of the ATNESA Workshop, Mpumalanga, South Africa, September 1999.

[17] Kenya National Bureau of Statistics, Baringo, Nakuru and Turkana County Statistical Abstracts, Kenya National Bureau of Statistics, Nairobi, Kenya, 2015.

[18] National Equine Welfare Council, "Equine industry welfare guidelines compendium for horses, ponies and donkeys," in Body Condition Scoring of Horses and Donkeys, pp. 28-29, National Equine Welfare Council, Somerton, UK, 2nd edition, 2005.

[19] E. J. L. Soulsby, Helminths, Arthropods and Protozoa of Domesticated Animals, The English linguar book society and Bailliere Tindal, London, UK, 7th edition, 1982.

[20] International Institute of Parasitology, International Institute of Parasitology: International training course on identification of helminth parasites of economic importance, Centre for Agriculture and Biosciences international, St. Albans, UK, 1994.

[21] MAFF, Ministry of Agriculture Fisheries and Food Manual of Veterinary Parasitological Techniques Technical Bulletin, HSMO, no. 18, St. Louis, MO, USA, 1986.

[22] N. Ibrahim, T. Berhanu, B. Deressa, and T. Tolosa, "Survey of prevalence of helminth parasites of donkeys in and around Hawassa Town, Southern Ethiopia," Global Veterinaria, vol. 3, pp. 223-227, 2011.

[23] A. K. Lewa, T. A. Ngatia, W. K. Munyua, and N. Maingi, "Common internal parasites encountered in donkeys in Kiambu District, Kenya," Kenya Veterinarian, vol. 21, no. 1, pp. 49-51, 2001.

[24] M. Getachew, A. Trawford, G. Feseha, and S. W. J. Reid, "Gastrointestinal parasites of working donkeys of Ethiopia," Tropical Animal Health and Production, vol. 42, no. 1, pp. 27-33, 2010.

[25] S. Yoseph, D. G. Smith, A. Mengistu, F. Teklu, T. Firew, and Y. Betere, "Seasonal variation in the parasite burden and body condition of working donkeys in East Shewa and West Shewa regions of Ethiopia," Tropical Animal Health and Production, vol. 37, no. 1, pp. 35-45, 2005.

[26] J. Vercruysse, E. A. Harris, Y. Y. Kaboret, L. J. Pangui, and D. I. Gibson, "Gastro-intestinal helminths of donkeys in Burkina Faso," Zeitschrift für Parasitenkunde, vol. 72, no. 6, pp. 821-825, 1986.

[27] J. B. Matthews and F. A. Burden, "Common helminth infections of donkeys and their control in temperate regions," Equine Veterinary Education, vol. 25, no. 9, pp. 461-467, 2013.

[28] P. N. B. De Souza, T. C. B. Bomfim, F. Huber, L. C. S. Abboud, and R. S. Gomes, "Natural infection by Cryptosporidium sp., Giardia sp. and Eimeria leuckarti in three groups of equines with different handlings in Rio de Janeiro, Brazil," Veterinary Parasitology, vol. 160, no. 3-4, pp. 327-333, 2009.

[29] X. X. Zhang, F. K. Zhang, F. C. Li et al., "The presence of Giardia intestinalis in donkeys, Equus asinus in China," Parasites \& Vectors, vol. 10, no. 1, p. 3, 2017.

[30] J. Nakayima, W. Kabasa, D. Aleper, and D. Okidi, "Prevalence of endo-parasites in donkeys and camels in Karamoja sub- 
region, North-Eastern Uganda," Journal of Veterinary Medicine and Animal Health, vol. 9, no. 1, pp. 11-15, 2017.

[31] M. M. Upjohn, K. Shipton, T. Lerotholi, G. Attwood, and K. L. P. Verheyen, "Coprological prevalence and intensity of helminth infection in working horses in Lesotho," Tropical Animal Health and Production, vol. 42, no. 8, pp. 1655-1661, 2010.

[32] M. A. Crane, K. Khallaayoune, C. Scantlebury, and R. M. Christley, "A randomized triple blind trial to assess the effect of an anthelmintic programme for working equids in Morocco," BMC Veterinary Research, vol. 7, no. 1, p. 1, 2011.

[33] N. Tesfu, B. Asrade, R. Abebe, and S. Kasaye, "Prevalence and risk factors of gastrointestinal nematode parasites of horse and donkeys in Hawassa Town, Ethiopia," Journal of Veterinary Science \& Technology, vol. 5, no. 5, 2014.

[34] M. M. Attia, M. M. Khalifa, and M. T. Atwa, "The prevalence and intensity of external and internal parasites in working donkeys (Equus asinus) in Egypt," Veterinary World, vol. 11, no. 9, pp. 1298-1306, 2018. 